\title{
Triaminotrinitrobenzene Isomers - A DFT Treatment
}

\section{Lemi Türker}

Department of Chemistry, Middle East Technical University, Üniversiteler, Eskişehir Yolu No: 1, 06800 Çankaya/Ankara, Turkey; e-mail: lturker@metu.edu.tr; lturker@gmail.com

\begin{abstract}
1,3,5-triamino-2,4,6-trinitrobenzene known as TATB is an insensitive high energy density material. It has two more constitutional isomers. The present study deals with all these triaminotrinitrobenzene isomers within the constraints of density functional theory at the levels of RB3LYP/6-31G(d,p) and UB3LYP/6-31G(d). Some geometrical and quantum chemical properties have been obtained and compared. The calculated IR and UV-VIS spectra are produced. Additionally the NICS values have been collected by calculating absolute NMR shielding values at the ring centers, $\operatorname{NICS}(0)$, and aromaticity of these isomers are compared. UB3LYP/6-31+G(d) level of calculations revealed that monoionic forms of these isomeric compounds are stable.
\end{abstract}

\section{Introduction}

Thermal stability is of main concern regarding to the formulation, processing, and handling of a high explosive (HE), but also important for its safety including fuel fires, propellant fires, and even a potential for sympathetic detonation. It has been long known that 1,3,5-triamino-2,4,6-trinitrobenzene (TATB) is a reasonably powerful high explosive having thermal and shock stability which is considerably greater than that any other known material of comparable energy. TATB was obtained years ago by Jacson and Wing by treating 1,3,5-tribromo-2,4,6-trinitrobenzene with cold alcoholic solution of ammonia [1, 2]. It decomposes at $360^{\circ} \mathrm{C}$ without melting [3]. It is a yellowbrown substance decomposing rapidly just below the melting point; but it has excellent

Received: November 5, 2018; Accepted: November 22, 2018

Keywords and phrases: triaminotrinitrobenzene, TATB, explosives, NICS, pull-push.

Copyright (C) 2019 Lemi Türker. This is an open access article distributed under the Creative Commons Attribution License, which permits unrestricted use, distribution, and reproduction in any medium, provided the original work is properly cited. 
thermal stability in the range $260-290^{\circ} \mathrm{C}$, which represents the upper temperature limit at which it may be used.

After II world war, research focused intensely on high energetic materials in order to produce safer and more heat resistant explosives [4]. One of the striking features of TATB is the strong and extensive hydrogen bonding, both inter- and intramolecular, between $\mathrm{NO}_{2}$ and $\mathrm{NH}_{2}$ groups [5,6] which contributes its stability. The first important work on the reason for this unique stability was done in 1965 by Cady and Larson, who determined the crystal structure of TATB [5]. Since then intense research has been done on TATB [7-18]. Beside the experimental studies on TATB, various computational works have been done on it [19-23].

In the present work, triaminotrinitrobenzene isomers are investigated quantum chemically within the limitations of density functional theory (DFT) at the levels of B3LYP/6-31G(d,p) and UB3LYP/6-31G(d) levels. Their monoionic forms have also been investigated at the level of UB3LYP/6-31+G(d).

\section{Method of Calculation}

Presently, geometry optimizations of all the structures leading to energy minima were initially achieved by using MM2 method followed by semi-empirical PM3 selfconsistent fields molecular orbital (SCF MO) method [24, 25] at the restricted level [26, 27]. Subsequent optimizations were achieved at Hartree-Fock level using various basis sets hierarchically. Then, the geometry optimizations were managed within the framework of density functional theory [28, 29], finally at the levels of RB3LYP/631G(d,p) and UB3LYP/6-31G(d) [26]. Note that the exchange term of B3LYP consists of hybrid Hartree-Fock and local spin density (LSD) exchange functions with Becke's gradient correlation to LSD exchange $[29,30]$. Note that the correlation term of B3LYP consists of the Vosko, Wilk, Nusair (VWN3) local correlation functional [31] and Lee, Yang, Parr (LYP) correlation correction functional [32]. The vibrational analyses have also been done. The total electronic energies are corrected for the zero point vibrational energy (ZPE). The stationary points to energy minima were proved in all the cases by calculation of the second derivatives of energy with respect to the atom coordinates. The normal mode analysis for each structure yielded no imaginary frequencies for the $3 \mathrm{~N}-6$ vibrational degrees of freedom, where $N$ is the number of atoms in the system. This indicates that the structure of each molecule corresponds to at least a local minimum on 
the potential energy surface. All these calculations were done by using the Spartan 06 package program [33].

For NICS data, the absolute NMR shielding values [34] were calculated by employing the Gauge-Independent Atomic Orbital method [35] with the restricted closed shell formalism at the level of B3LYP/6-31G(d,p). The NICS values have been collected by calculating absolute NMR shielding values at the ring centers, NICS $(0)$.

The NICS $(0)$ calculations of the present systems have been performed by the use of Gaussian 03 package program [36]. The monoionic forms of the isomers considered have been investigated at the level of UB3LYP/6-31+G(d).

\section{Results and Discussion}

\subsection{Structures}

Triaminotrinitrobenzene has three structural isomers. In the present study, they are called TATB and TATB isomers. Based on the position of the amino groups, the isomers are called 123-TATB and 124-TATB. 135-TATB is simply called TATB which is actually 1,3,5-triamino-2,4,6-trinitrobenzene.
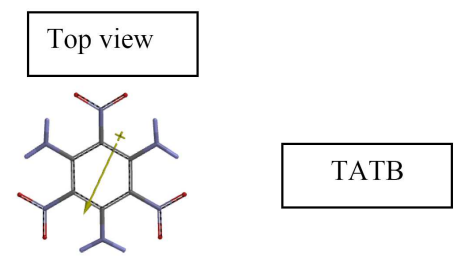

Side view<smiles>CCC1C(C(C)C)C(C(C)C)C(C(C)C)C1C(C)C</smiles>

123-TATB
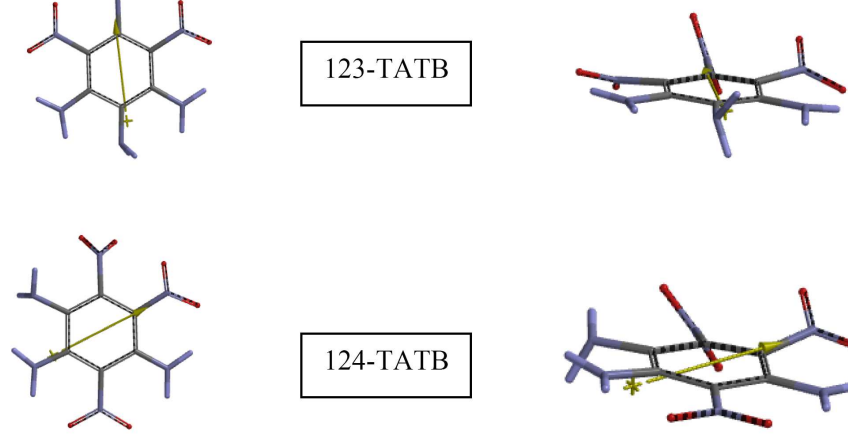

124-TATB

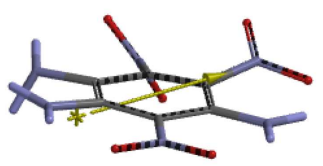

Figure 1. Optimized structures of triaminotrinitrobenzene isomers considered (B3LYP/6-31G(d,p). 
Figure 1 shows the optimized structures as well as the dipole moment vectors of triaminotrinitrobenzene isomers considered. As seen in the figure, although TATB more or less has coplanar substituents with the aromatic ring, the others do not.

\subsection{Bond lengths}

Figure 2 shows the bond lengths of the structures. Although bond lengths of TATB ring are equal, in the case of other isomers they vary. Also, $\mathrm{C}-\mathrm{NH}_{2}$ and $\mathrm{C}-\mathrm{NO}_{2}$ bond lengths vary in 123-TATB and 124-TATB depending on their positions.

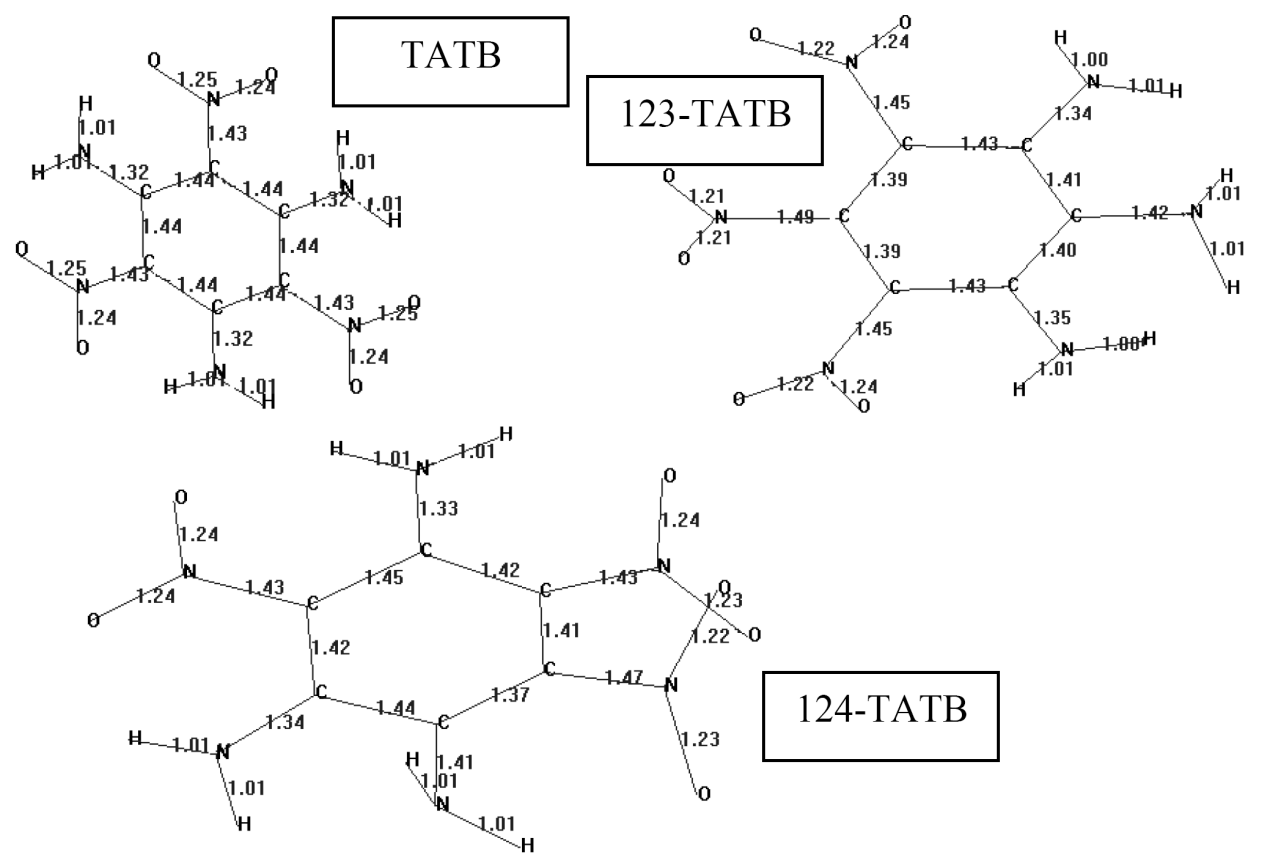

Figure 2. Bond lengths of the TATB isomers considered (B3LYP/6-31G(d,p)).

\subsection{Electrostatic charges and some properties}

Figure 3 shows the charge distribution (ESP) on the structures considered. The ESP charges are obtained by the program based on a numerical method that generates charges that reproduce the electrostatic potential field from the entire wavefunction [33]. 


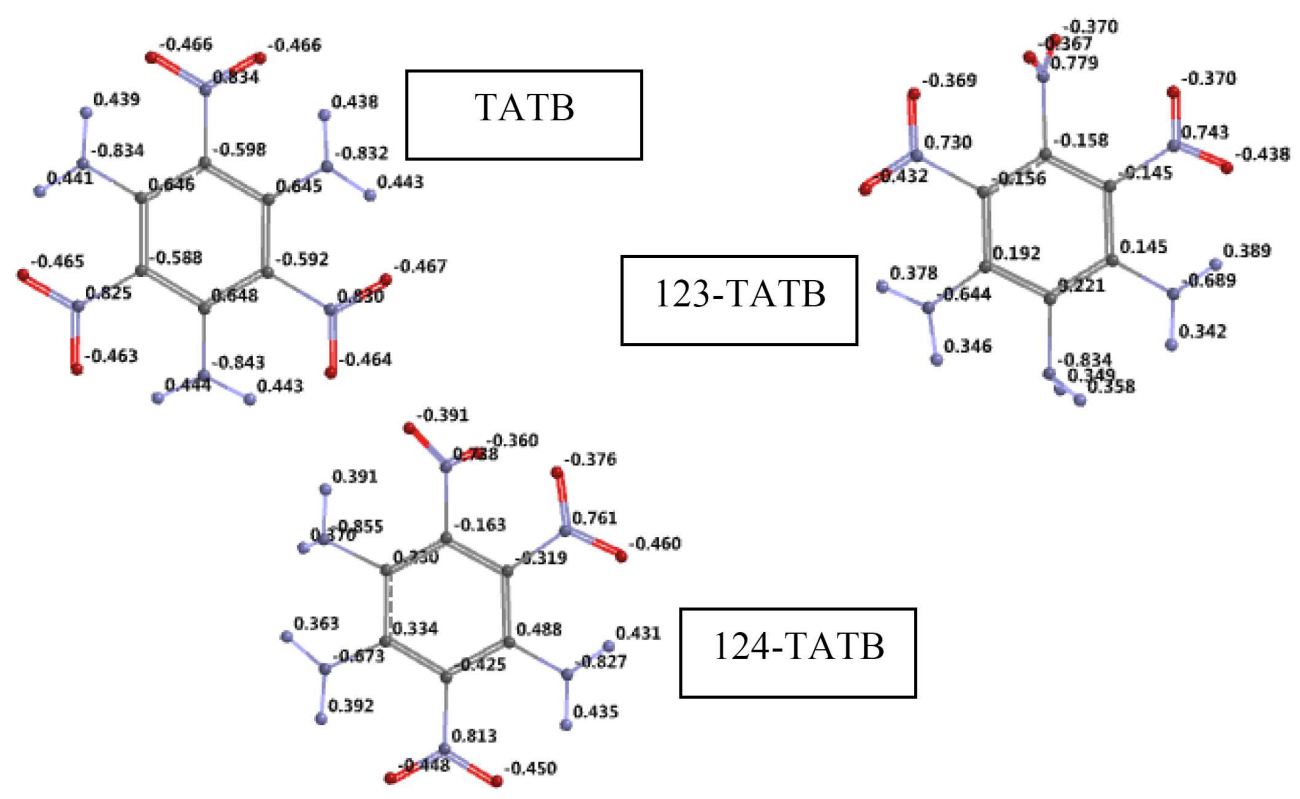

Figure 3. Charge distribution (ESP) on of the structures considered (B3LYP/6-31G(d,p).

Table 1 shows the various properties of TATB isomers. All the properties listed in the table follow the order of TATB $<124$-TATB $<123$-ТATB with the exception of polarizability data.

Table 1. Various properties of TATB isomers.

\begin{tabular}{lcccc}
\hline Molecule & $\begin{array}{c}\text { Dipole moment } \\
(\text { Debye })\end{array}$ & $\begin{array}{c}\text { Area } \\
\left(\AA^{2}\right)\end{array}$ & $\begin{array}{c}\text { Volume } \\
\left(\AA^{3}\right)\end{array}$ & $\begin{array}{c}\text { Polarizability } \\
\left(\AA^{3}\right)\end{array}$ \\
\hline TATB & 0.01 & 206.88 & 188.01 & 55.88 \\
123-TATB & 10.81 & 221.66 & 193.27 & 56.13 \\
$124-$ TATB & 5.45 & 215.90 & 191.50 & 56.14 \\
\hline
\end{tabular}

\subsection{Stabilities}

Table 2 displays various energies of TATB isomers. The restricted and unrestricted level of calculations indicate the stability order of TATB $>124-$ TATB $>123-$ TATB. The highest stability of TATB among the others might be due to highly symmetrical location of the strongly electron donor $\left(\mathrm{NH}_{2}\right)$ and strongly electron acceptor $\left(\mathrm{NO}_{2}\right)$ groups. So that the resonance assisted intramolecular hydrogen bonding $[19,20]$ might occur. 
Table 2. Various energies of TATB isomers.

\begin{tabular}{lcccccc}
\hline & \multicolumn{3}{c}{ RB3LYP/6-31G(d,p) } & \multicolumn{3}{c}{ UB3LYP/6-31G(d) } \\
\hline Molecule & $\mathbf{E}$ & $\mathbf{Z P E}$ & $\mathbf{\mathbf { E } _ { \mathbf { c } }}$ & $\mathbf{E}$ & $\mathbf{Z P E}$ & $\mathbf{E}_{\mathbf{c}}$ \\
TATB & -2656630.71 & 416.85 & -2656213.86 & -2656569.90 & 419.12 & -2656150.78 \\
123-TATB & -2656499.38 & 415.17 & -2656084.21 & -2656444.62 & 415.63 & -2656028.99 \\
124-TATB & -2656544.99 & 418.07 & -2656126.92 & -2656489.56 & 418.77 & -2656070.79 \\
\hline
\end{tabular}

Energies in $\mathrm{kJ} / \mathrm{mol}$.

\subsection{Spectra}

Figure 4 shows the calculated (B3LYP6-31G(d,p)) IR spectra of TATB isomers. TATB has asymmetric and symmetrical N-H stretchings at 3543 and $3414 \mathrm{~cm}^{-1}$, respectively. The respective stretchings of 123-TATB occur at 3723, 3701 (asymmetrical) and 3555 (symmetrical) $\mathrm{cm}^{-1}$. 124-TATB has those bands at 3670, 3629 (asymmetrical) and 3526, 3481 (symmetrical) $\mathrm{cm}^{-1}$. TATB ring vibrations occur at 1634 $\mathrm{cm}^{-1}$. In the case of 123-TATB the ring stretchings and $\mathrm{C}-\mathrm{NH}_{2}$ stretchings coupled and happens at $1673 \mathrm{~cm}^{-1}$. The nearby peaks at $1643 \mathrm{~cm}^{-1}$ are $\mathrm{NH}_{2}$ bendings and N-O stretchings coupled with $\mathrm{C}-\mathrm{NO}_{2}$ bendings. The sharp peak at $1332 \mathrm{~cm}^{-1}$ is due to various stretching and bending modes. As for the 124 -isomer, the peaks at 3670 and $3629 \mathrm{~cm}^{-1}$ are asymmetrical N-H stretchings, followed by symmetrical ones at 3526 and $3481 \mathrm{~cm}^{-1}$. The region of $1667-1278 \mathrm{~cm}^{-1}$ includes various stretching and bending modes. 

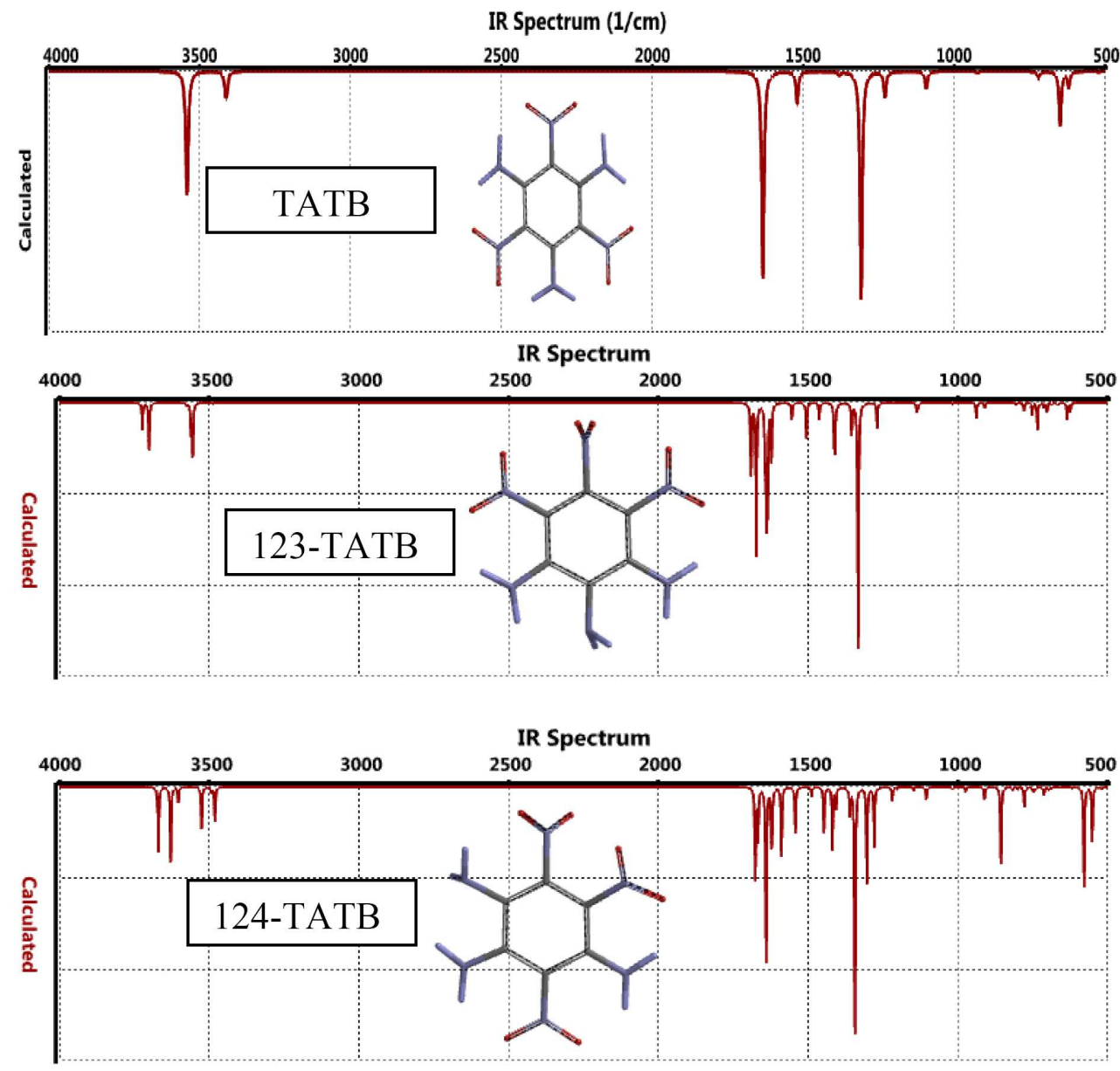

Figure 4. IR spectra of the TATB isomers (B3LYP6-31G(d,p)).

Figure 5 shows the time-dependent (TDDFT, B3LYP6-31G(d,p)) UV-VIS spectra of the structures considered. As seen in the figure, TATB is distinctly different than the other isomers. 123- and 124-isomers contrary to TATB exhibit spectra having more than one $\lambda_{\max }$ value. Also they show bathochromic effect. Consequently, the isomers are expected to be more colorful compared to TATB itself. 

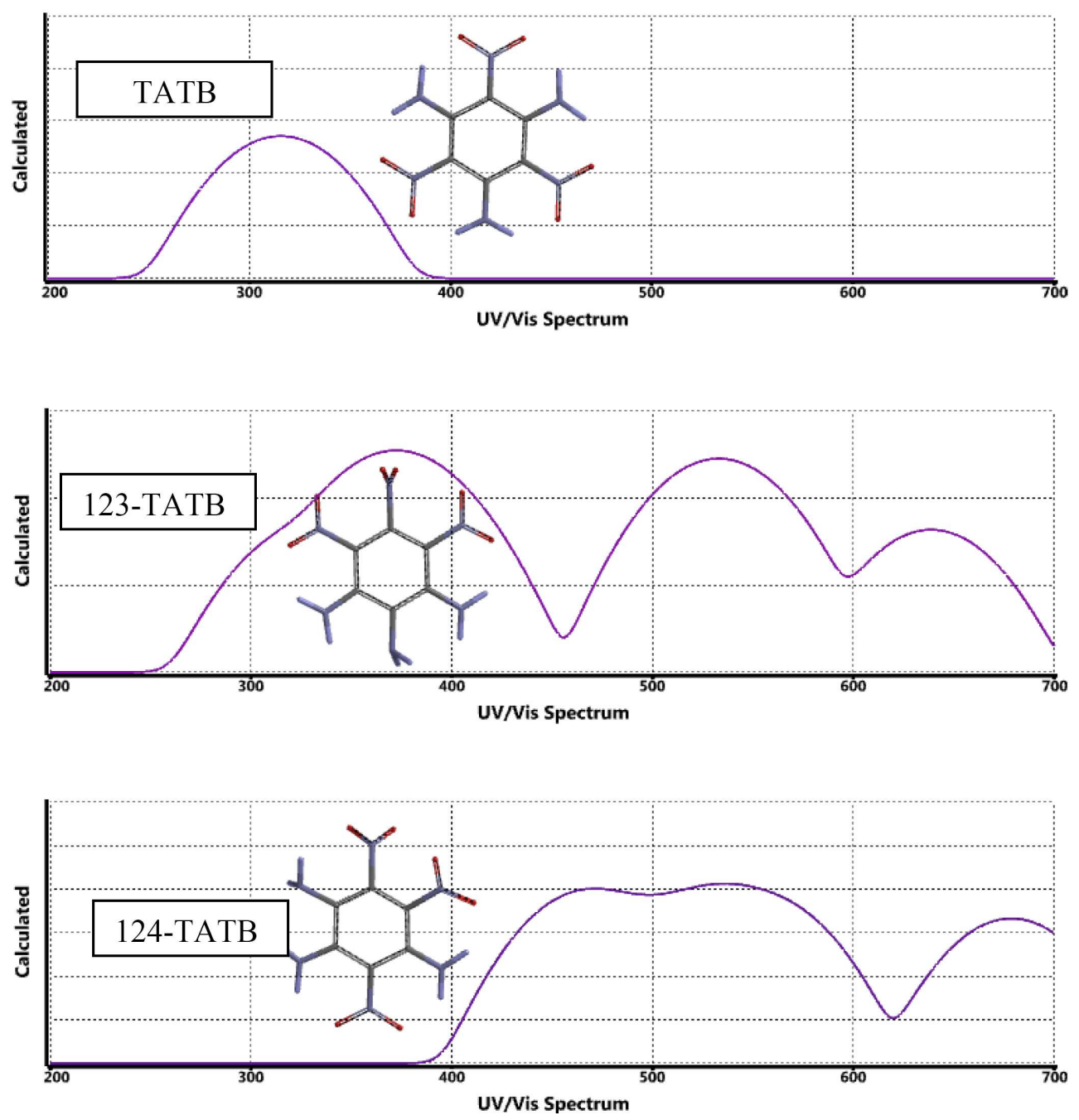

Figure 5. UV-VIS spectra of the TATB isomers (B3LYP6-31G(d,p)).

\subsection{NICS}

Note that the simplest criterion for aromaticity of compounds is that the presence of cyclic conjugated $\pi$-systems containing the proper number of $\pi$-electrons (i.e., the Hückel rule). In spite of the fact that this criterion is enough to predict the aromaticity of monocyclic neutral or charged ring systems, it is not always appropriate as a clear indicator of aromaticity for more complex systems.

Aromaticity arises by a combination of various properties in cyclic delocalized systems. In general, aromaticity is discussed in terms of energetic, structural and 
magnetic criteria [37-42]. Schleyer, in 1996, has introduced a simple and efficient probe for aromaticity that is "nucleus-independent chemical shift" (NICS) [43]. It is the computed value of the negative magnetic shielding at some selected point in space which is generally, at a ring or cage center. The calculated data piled in the literature indicate that negative NICS values denote aromaticity (-11.5 for benzene, -11.4 for naphthalene) contrary to positive NICS values which denote antiaromaticity ( 28.8 for cyclobutadiene) while small NICS values indicate non-aromaticity (-2.1 for cyclohexane, -1.1 for adamantane). NICS may be a useful indicator of aromaticity such that it usually correlates successfully with the other energetic, structural and magnetic criteria for aromaticity [44-47]. Although the resonance energies and magnetic susceptibilities are measures of the overall aromaticity of a polycycle, they do not provide information about the individual rings. In contrast, NICS has been proved to be an effective probe for local aromaticity of individual rings of polycyclic systems.

In the present study, NICS(0) values of the isomers considered have been calculated at the level of B3LYP/6-31G(d,p). The results for TATB, 123-TATB and 124-TATB are $-6.0929,-9.6718$ and -8.8503 , respectively. Thus, the order of aromaticity is 123-TATB $>124-\mathrm{TATB}>$ TATB . The results reveal that alternatingly substituted $\mathrm{NH}_{2}$ and $\mathrm{NO}_{2}$ groups in TATB cause such a pull-push effect that the ring current for the aromaticity is less effective than the others indicating that resonance structure II [20] contributes the resonance hybrid up to a certain extent. Note that resonance structure II allows resonance assisted intramolecular hydrogen bonding $[19,20]$ and as mentioned above it should be responsible for the higher stability of TATB among them.

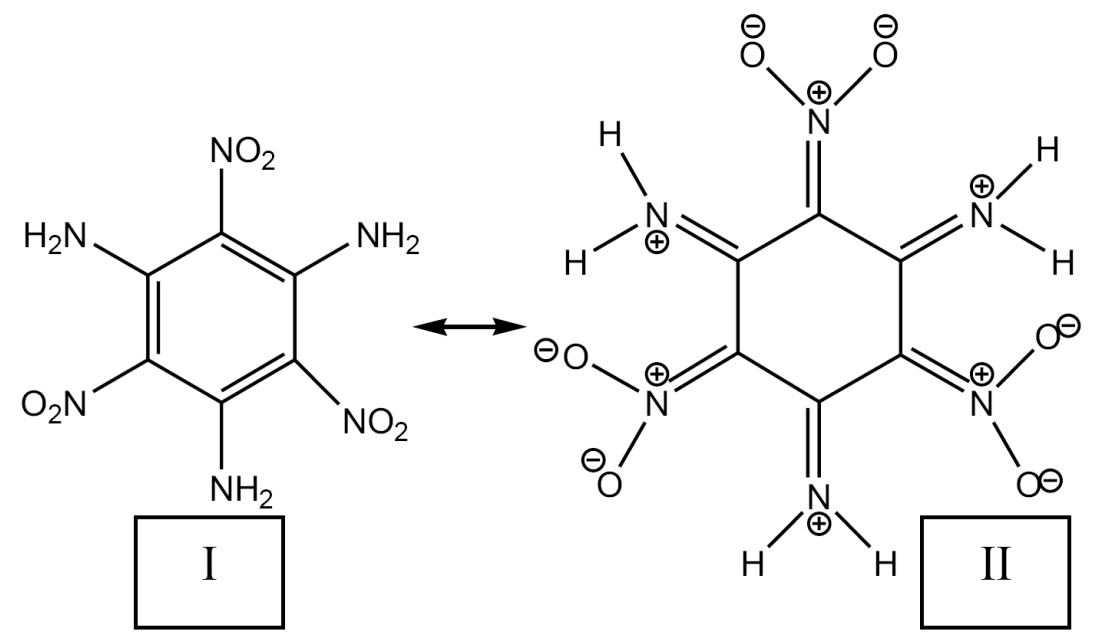




\subsection{Frontier molecular orbitals and energies}

Table 3 tabulates the frontier molecular orbital energies (HOMO and LUMO) and interfrontier molecular orbital energy gaps $(\boldsymbol{\Delta} \boldsymbol{\varepsilon})$ for the isomers considered. The order of HOMO and LUMO energies are TATB $<123$-TATB $<124-$ TATB and 124-TATB $<123-$ TATB $<$ TATB, respectively. Whereas $\boldsymbol{\Delta} \boldsymbol{\varepsilon}$ values follow the order of 124-TATB $<123-$ TATB $\angle$ TATB. Note that the impact sensitivity is generally correlated with the HOMOLUMO energy gap [48]. Thus, the isomers of TATB should exhibit impact sensitivities parallel to reverse order of $\Delta \varepsilon$ values.

Table 3. Frontier molecular orbital energies and interfrontier molecular orbital energy gaps for the isomers considered.

\begin{tabular}{lccc}
\hline Molecule & HOMO & LUMO & $\boldsymbol{\Delta} \boldsymbol{\varepsilon}$ \\
\hline TATB & -698.51 & -271.60 & 426.91 \\
123-TATB & -660.40 & -285.86 & 374.54 \\
124-TATB & -624.64 & -310.89 & 313.75 \\
\hline
\end{tabular}

RB3LYP/6-31G(d,p) level of calculation. Energies in $\mathrm{kJ} / \mathrm{mol}$.

The HOMO and LUMO energy levels of TATB are lower compared to the other isomers. This might be due to more pronounced electron attracting effect of $\mathrm{NO}_{2}$ groups than the electron donating effect of $\mathrm{NH}_{2}$ groups. Note that electron donating groups (like $\mathrm{NO}_{2}$ ) lower both the HOMO and LUMO energy levels while the electron donors (like $\mathrm{NH}_{2}$ ) have an opposite effect [49].

Figure 6 shows some of the molecular orbital energy distribution of the isomers. As seen in the figure, position of the donor and acceptor groups are highly effective on the distribution of molecular orbital energy levels especially on the inner lying occupied molecular orbitals which dictate the thermal stability of structures. 

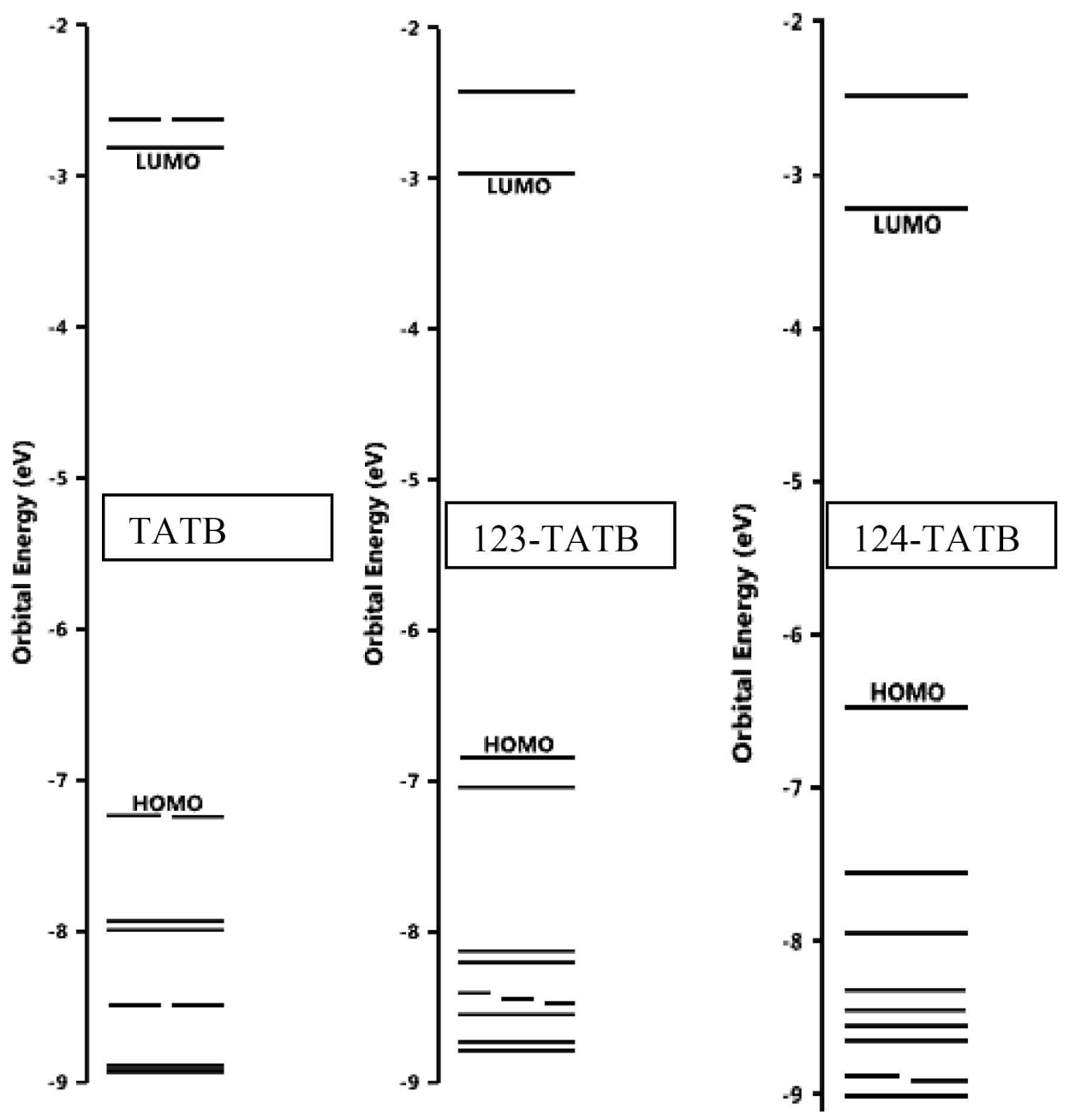

Figure 6. Some molecular orbital energies of the isomers (RB3LYP/6-31G(d,p)).

Figure 7 shows the HOMO and LUMO pattern of the isomers. As seen in the figure, although LUMO of TATB is characterized with localized orbitals on atoms, for others either the HOMO or LUMO spread over the other atoms up to a certain extent which might have some effect on their UV-VIS spectra. 

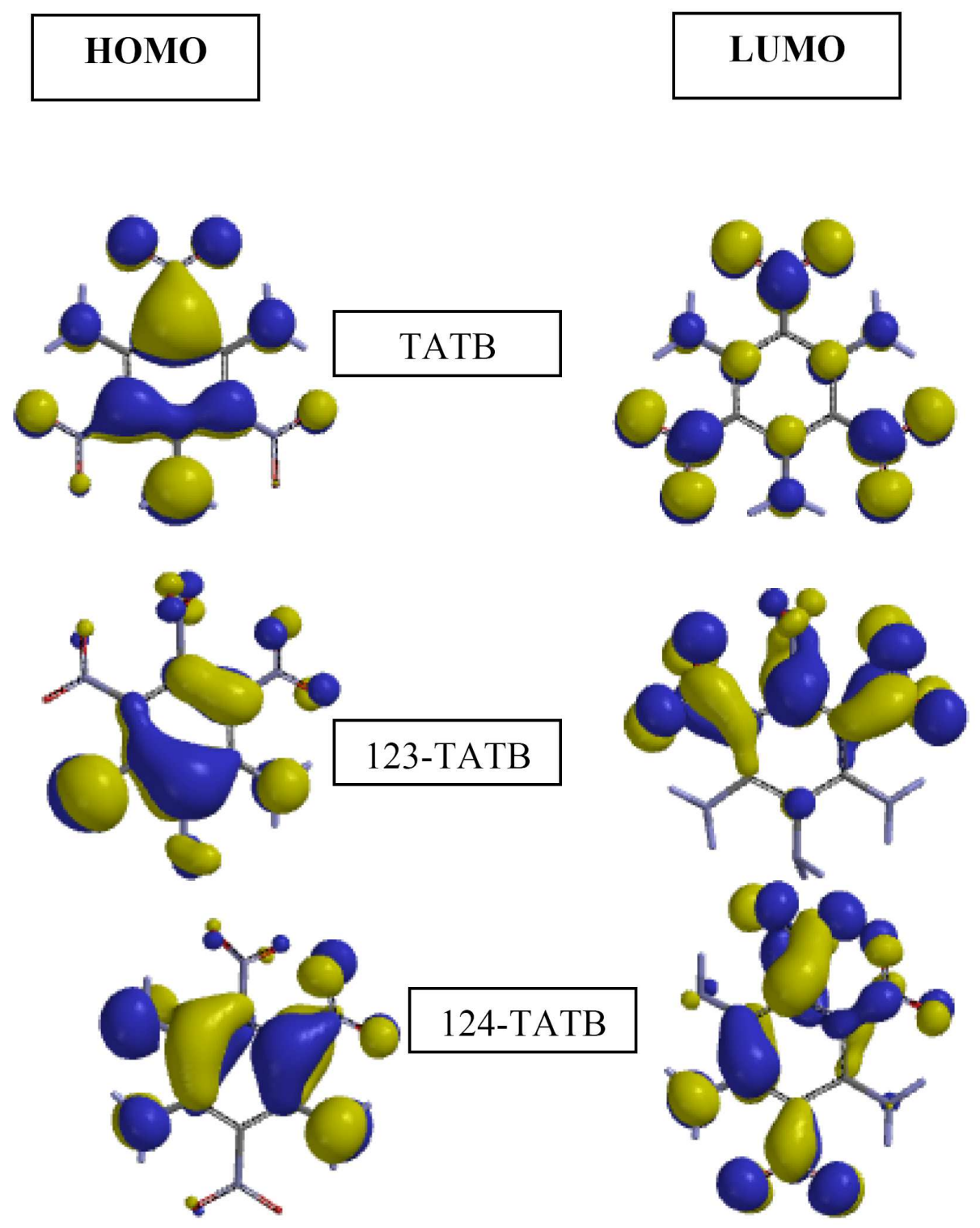

Figure 7. The HOMO and LUMO pattern of the isomers considered (RB3LYP/6$31 G(d, p))$.

Figure 8 stands for the electrostatic potential maps of the isomers considered. As seen in the figure TATB is characterized with less electron density in the ring but more on the peripheral groups compared to the others. This is in parallel to the NICS results which yields the order of aromaticity as 123-TATB>124-TATB>TATB. 

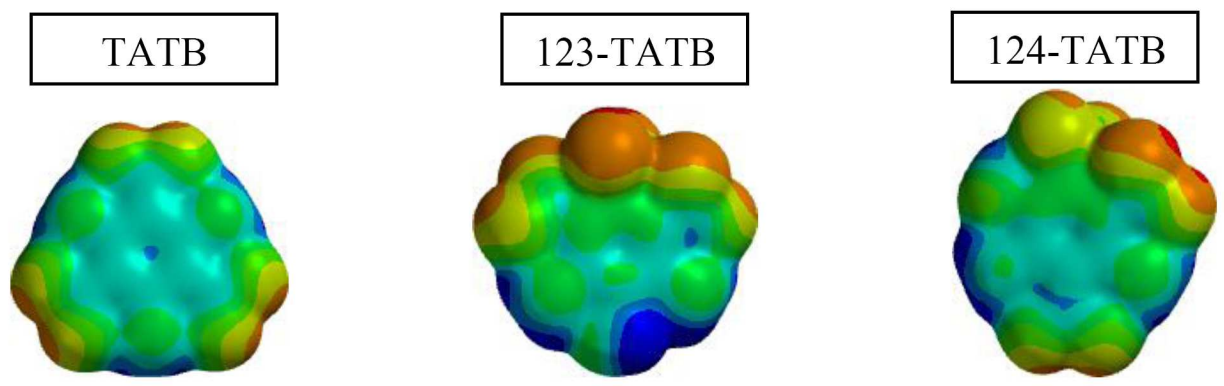

Figure 8. Electrostatic potential maps of the isomers considered (RB3LYP/6-31G(d,p)).

\subsection{Charged forms}

Figure 9 shows the optimized structures of monoionic triaminotrinitrobenzene isomers considered. It shows that both the anions and cations are intact structures. In some of them the hexagonal ring is slightly puckered. Most of the nitro groups are not coplanar with the core. In the case of 124-TATB one of the $\mathrm{NO}_{2}$ groups is out of the plane of the ring. These structural variations are small perturbations hence TATB isomers are stable to monocharging in an electric field.
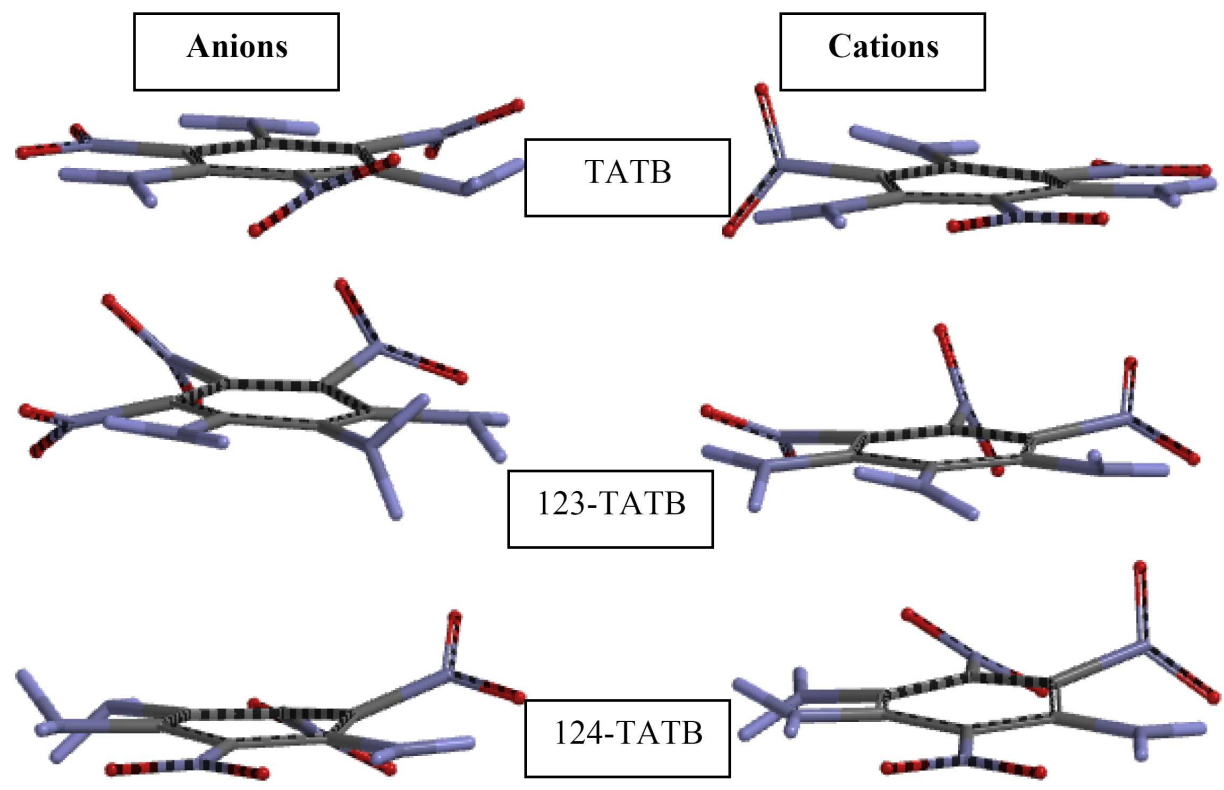

Figure 9. Optimized structures of ionic triaminotrinitrobenzene isomers considered (UB3LYP/6-31+G(d)). 
Table 4 shows the various energies of the ionic forms. The stability orders of the anions and cations are TATB $>124-$ TATB $>123-$ TATB and 124-TATB $>$ TATB $>123-$ TATB, respectively. Hence, TATB can accommodate a negative charge better than a positive one. Whereas, 1,2,3-TATB is the least stable so it is the most sensitive to monoionic charging within the group.

Table 4. Various energies of the ionic forms.

\begin{tabular}{lcccccc}
\hline & \multicolumn{3}{c}{ Anion } & \multicolumn{3}{c}{ Cation } \\
\hline Molecule & $\mathbf{E}$ & $\mathbf{Z P E}$ & $\mathbf{E}_{\mathbf{c}}$ & $\mathbf{E}$ & $\mathbf{Z P E}$ & $\mathbf{E}_{\mathbf{c}}$ \\
\hline TATB & -2656876.60 & 407.88 & -2656468.72 & -2655826.34 & 414.83 & -2655411.51 \\
123-TATB & -2656773.69 & 407.13 & -2656366.56 & -2655766.18 & 412.18 & -2655354.00 \\
124-TATB & -2656855.57 & 412.38 & -2656443.19 & -2655832.29 & 416.66 & -2655415.63 \\
\hline
\end{tabular}

UB3LYP/6-31+G(d) level. Energies in $\mathrm{kJ} / \mathrm{mol}$.

Table 5 displays the frontier molecular orbital energies and the energy gap in between them for the mono ionic forms of the isomers considered. The HOMO and LUMO energy orders are 124-TATB $<123-$ TATB $<$ TATB and TATB $<124$-TATB $<123-$ TATB, respectively for the anions. Consequently the order of energy gap, $\Delta \boldsymbol{\varepsilon}$, becomes 124-TATB $>123-$ TATB $>$ TATB.

Table 5. Frontier molecular orbital energies and interfrontier molecular orbital energy gaps for the ionic forms of the isomers considered.

\begin{tabular}{lcccccc}
\hline & \multicolumn{3}{c}{ Anion } & \multicolumn{3}{c}{ Cation } \\
\hline Molecule & HOMO & LUMO & $\boldsymbol{\Delta} \boldsymbol{\varepsilon}$ & HOMO & LUMO & $\boldsymbol{\Delta} \boldsymbol{\varepsilon}$ \\
\hline TATB & -67.19 & 28.12 & 95.31 & -1168.44 & -756.94 & 411.5 \\
123-TATB & -81.66 & 83.52 & 165.18 & -1123.60 & -706.64 & 416.96 \\
124-TATB & -126.92 & 64.11 & 191.03 & -1080.10 & -763.88 & 316.22 \\
\hline
\end{tabular}

UB3LYP/6-31+G(d) level. Energies in kJ/mol.

As for the cations, the HOMO and LUMO energy orders are TATB $<123$ TATB $<124-\mathrm{TATB}$ and 124-TATB $<$ TATB $<123$-TATB, respectively. Whereas, the order of $\boldsymbol{\Delta} \boldsymbol{\varepsilon}$ for them is 123-TATB $>$ TATB $>124-\mathrm{TATB}$.

\section{Conclusion}

Triaminotrinitrobenzene isomers presently considered are found to be stable, irrespective of the restricted and unrestricted level of DFT calculations (RB3LYP/6$31 \mathrm{G}(\mathrm{d}, \mathrm{p})$ and UB3LYP/6-31G(d)) which yield the stability order of TATB>124TATB $>123-T A T B$. The calculated IR and UV-VIS spectra indicate that TATB is 
distinctly different than the other isomers. Especially its UV-VIS spectra is confined to UV region whereas the others show bathochromic effect thus absorb highly in the visible region. The stability orders of the anions and cations are TATB $>124-$ TATB $>123-$ TATB and 124-TATB $>$ TATB $>123-$ TATB, respectively. The results reveal that TATB isomers are stable to monocharging in an electric field being 1,2,3-TATB the least stable than others in the set to the negative as well as the positive charging.

\section{References}

[1] C. L. Jacson and J. F. Wing, On tribromonitrobenzol (LIX), J. Am. Chem. Soc. 10 (1888), 283.

[2] C. L. Jacson and J. F. Wing, On the action of nitric acid on symmetrical trichlorobenzene (LIII), J. Am. Chem. Soc. 10 (1887), 348.

[3] R. Meyer, J. Köhler and A. Homburg, Explosives, Weinheim: Wiley-VCH, 2002.

[4] F. Taylor, Jr., Synthesis of new high energy explosives (II), derivatives of 1,3,5-tribromo2,4,6-trinitrobenzene, US Naval Ordnance Laboratory Report, NAVORD 4405, 1956.

[5] H. Cady and A. C. Larson, The crystal structure of 1,3,5-triamino,-2,4,6-trinitrobenzene, Acta Cryst. 18 (1965), 485-496.

[6] W. M. Trott and A. M. Renlund, Single-pulse Raman scattering study of triaminotrinitrobenzene under shock compression, J. Phys. Chem. 92(21) (1988), 59215925 .

[7] V. D. Gupta and B. L. Deopura, Low-frequency neutron spectrum of 1,3,5-triamino2,4,6-trinitrobenzene, Mol. Phys. 19 (1970), 589-592.

[8] B. L. Deopura and V. D. Gupta, Vibration spectra of 1,3,5-triamino-2,4,6-trinitrobenzene, J. Chem. Phys. 54 (1970), 4013-4019.

[9] J. R. Kolb and H. F. Rizzo, Growth of 1,3,5-triamino-2,4,6,-trinitrobenzene (TATB). I. Anisotropic thermal expansion, Prop. Exp. 4 (1979), 10-16.

[10] A. D. Britt, W. B. Moniz, G. C. Chingas, D. W. Moore, C. A. Heller and C. L. Ko, Free radicals of TATB, Prop. Exp. 6 (1981), 94-95.

[11] T. G. Towns, Vibrational spectrum of 1,3,5-triamino-2,4,6-trinitrobenzene, Spectrochim. Acta 39A (1983), 801-804.

[12] M. Farber and R. D. Srivastava, Thermal decomposition of TATB, Combustion and Flame 42 (1981), 165-171. 
[13] J. Sharma, W. L. Garrett, F. J. Owens and V. L. Vogel, X-ray photoelectron study of electronic structure and ultraviolet and isothermal decomposition of TATB, J. Phys. Chem. 86 (1982), 1657-1661.

[14] E. Catalano and P. Crawford, An enthalpic study of the thermal decomposition of TATB, Thermochim Acta 61 (1983), 23-36.

[15] P. C. Harihan, W. S. Koski, J. J. Kaufman and R. S. Miller, Ab initio MODPOT/VRDDO/MERGE calculations on energetic compounds, III. Nitroexplosives: Polyaminopolynitrobenzenes (including DATD, TATB, and tetryl), Int. J. Quant. Chem. 23 (1983), 1493-1504.

[16] A. J. Davidson, R. P. Dias, D. M. Dattelbaum and C. S. Yoo, "Stubborn" triaminotrinitrobenzene: unusually high chemical stability of a molecular solid to 150 GPa, The Journal of Chemical Physics 135 (2011), 174507/1-174507/5. https://doi.org/10.1063/1.3658385.

[17] D. A. Tariq, The reactants equation of state for the tri-amino-tri-nitro-benzene (TATB) based explosive PBX 9502, Journal of Applied Physics 122 (2017), 035902/1-035902/8. https://doi.org/10.1063/1.498938.

[18] L. L. Stevens, N. Velisavljevic, D. E. Hooks and D. M. Dattelbaum, Hydrostatic compression curve for triamino-trinitrobenzene determined to $13.0 \mathrm{GPa}$ with powder Xray diffraction, Prop. Explos. Pyrotech. 30(4) (2008), 286-295.

[19] M. R. Manaa and L. E. Fried, Internal rotation in energetic systems: TATB, J. Phys. Chem. A 105(27) (2001), 6765-6768.

[20] I. V. Omelchenko, O. V. Shishkin, L. Gorb, F. Hill and J. Leszczynski, Properties, aromaticity, and substituents effects in poly nitro- and amino-substituted benzenes, Struct. Chem. 23 (2012), 1585-1597.

[21] C. Zhang, X. Cao and B. Xiang, Sandwich complex of TATB/Graphene: An approach to molecular monolayers of explosives, J. Phys. Chem. C 114(51) (2010), 22684-22687.

[22] R. S. Patil, S. Radhakrishnan, P. M. Jadhav, V. D. Ghule and T. Soman, Quantumchemical studies on TATB processes, Journal of Energetic Materials 28(2) (2010), 98113.

[23] R. Ahmadi, Study of thermodynamic parameters of (TATB) and its fullerene derivatives with different number of Carbon (C20, C24, C60), in different conditions of temperature, using density functional theory, Int. J. Nano Dimens. 8(3) (2017), 250-256.

[24] J. J. P. Stewart, Optimization of parameters for semiempirical methods I. Method, $J$. Comput. Chem. 10 (1989), 209-220. 
[25] J. J. P. Stewart, Optimization of parameters for semi empirical methods II. Application, J. Comput. Chem. 10 (1989), 221-264.

[26] A. R. Leach, Molecular Modeling, Essex: Longman, 1997.

[27] P. Fletcher, Practical Methods of Optimization, New York: Wiley, 1990.

[28] W. Kohn and L. Sham, Self-consistent equations including exchange and correlation effects, J. Phys. Rev. 140 (1965), 1133-1138.

[29] R. G. Parr and W. Yang, Density Functional Theory of Atoms and Molecules, London: Oxford University Press, 1989.

[30] A. D. Becke, Density-functional exchange-energy approximation with correct asymptotic behavior, Phys. Rev. A 38 (1988), 3098-3100.

[31] S. H. Vosko, L. Vilk and M. Nusair, Accurate spin-dependent electron liquid correlation energies for local spin density calculations: a critical analysis, Can. J. Phys. 58 (1980), 1200-1211.

[32] C. Lee, W. Yang and R. G. Parr, Development of the Colle-Salvetti correlation-energy formula into a functional of the electron density, Phys. Rev. B 37 (1988), 785-789.

[33] SPARTAN 06, Wavefunction Inc., Irvine CA, USA, 2006.

[34] P. J. Pulay, F. Hinton and K. Wolinski, Nuclear Magnetic Shieldings and Molecular Structure, Tossel, J. A. (Ed.), NATO ASI Series C, vol. 386, Netherlands: Kluwer, 1993, pp. 243.

[35] W. J. Hehre, L. Radom, P. R. Schleyer and J. A. Pople, Ab Initio Molecular Orbital Theory, New York: Wiley, 1986.

[36] Gaussian 03, Revision C.02, M. J. Frisch, G. W. Trucks, H. B. Schlegel, G. E. Scuseria, M. A. Robb, J. R. Cheeseman, J. A. Montgomery, Jr., T. Vreven, K. N. Kudin, J. C. Burant, J. M. Millam, S. S. Iyengar, J. Tomasi, V. Barone, B. Mennucci, M. Cossi, G. Scalmani, N. Rega, G. A. Petersson, H. Nakatsuji, M. Hada, M. Ehara, K. Toyota, R. Fukuda, J. Hasegawa, M. Ishida, T. Nakajima, Y. Honda, O. Kitao, H. Nakai, M. Klene, X. Li, J. E. Knox, H. P. Hratchian, J. B. Cross, V. Bakken, C. Adamo, J. Jaramillo, R. Gomperts, R. E. Stratmann, O. Yazyev, A. J. Austin, R. Cammi, C. Pomelli, J. W. Ochterski, P. Y. Ayala, K. Morokuma, G. A. Voth, P. Salvador, J. J. Dannenberg, V. G. Zakrzewski, S. Dapprich, A. D. Daniels, M. C. Strain, O. Farkas, D. K. Malick, A. D. Rabuck, K. Raghavachari, J. B. Foresman, J. V. Ortiz, Q. Cui, A. G. Baboul, S. Clifford, J. Cioslowski, B. B. Stefanov, G. Liu, A. Liashenko, P. Piskorz, I. Komaromi, R. L. Martin, D. J. Fox, T. Keith, M. A. Al-Laham, C. Y. Peng, A. Nanayakkara, M. Challacombe, P. M. W. Gill, B. Johnson, W. Chen, M. W. Wong, C. Gonzalez, and J. A. Pople, Gaussian, Inc., Wallingford CT, 2004. 
[37] V. I. Minkin, M. N. Glukhovtsev and B. Y. Simkin, Aromaticity and Antiaromaticity: Electronic and Structural Aspects, New York: Wiley, 1994.

[38] P. R. Schleyer and H. Jiao, Introduction: aromaticity, Pure Appl. Chem. 68 (1996), 209218.

[39] M. N. Glukhovtsev, Aromaticity today: energetic and structural criteria, J. Chem. Educ. 74 (1997), 132-136.

[40] T. M. Krygowski, M. K. Cyranski, Z. Czarnocki, G. Hafelinger and A. R. Katritzky, Aromaticity: a theoretical concept of immense practical importance, Tetrahedron 56 (2000), 1783-1796.

[41] P. R. Schleyer, Introduction: aromaticity, Chem. Rev. 101 (2001), 1115-1118.

[42] M. K. Cyranski, T. M. Krygowski, A. R. Katritzky and P. R. Schleyer, To what extent can aromaticity be defined uniquely?, J. Org. Chem. 67 (2002), 1333-1338.

[43] P. R. Schleyer, C. Maerker, A. Dransfeld, H. Jiao and N. J. R. E. Hommes, Nucleusindependent chemical shifts: A simple and efficient aromaticity probe, J. Am. Chem. Soc. 118 (1996), 6317-6318.

[44] H. Jiao and P. R. Schleyer, Aromaticity of pericyclic reaction transition structures: magnetic Evidence, J. Phys. Org. Chem. 11 (1998), 655-662.

[45] P. R. Schleyer, B. Kiran, D. V. Simion and T. S. Sorensen, Does $\mathrm{Cr}(\mathrm{CO})_{3}$ complexation reduce the aromaticity of benzene?, J. Am. Chem. Soc. 122 (2000), 510-513.

[46] D. Quinonero, C. Garau, A. Frontera, P. Ballaster, A. Costa and P. M. Deya, Quantification of aromaticity in oxocarbons: The problem of the fictitious "nonaromatic" reference system, Chem. Eur. J. 8 (2002), 433-438.

[47] S. Patchkovskii and W. Thiel, Nucleus-independent chemical shifts from semiempirical calculations, J. Mol. Model. 6 (2002), 67-75.

[48] N. R. Badders, C. Wei, A. A. Aldeep, W. J. Rogers and M. S. Mannan, Predicting the impact sensitivity of polynitro compounds using quantum chemical descriptors, $J$. Energetic Materials 24 (2006), 17-33.

[49] I. Fleming, Frontier Orbitals and Organic Chemical Reactions, London: Wiley, 1976. 